\title{
EVALUATION OF THE APICAL INFILTRATION AFTER ROOT CANAL DISRUPTION AND OBTURATION
}

\author{
João Eduardo GOMES-FILHO ${ }^{1}$, Renato Nicolás HOPP², Pedro Felício Estrada BERNABÉ ${ }^{3}$, Mauro Juvenal NERY ${ }^{1}$, \\ José Arlindo OTOBONI FILHO ${ }^{1}$, Elói DEZAN JÚNIOR ${ }^{1}$
}

\author{
1- DDS, MSc, PhD, Associate Professor, Department of Endodontics, Dental School of Araçatuba, State University of São Paulo, Araçatuba, \\ SP, Brazil. \\ 2- DDS, Department of Endodontics, Dental School of Araçatuba, State University of São Paulo, Araçatuba, SP, Brazil. \\ 3- DDS, MSc, PhD, Chairman, Dental School of Araçatuba, State University of São Paulo, Araçatuba, SP, Brazil.
}

Corresponding address: Dr. Renato Nicolás Hopp - Rua Simoneto Biagioni, 653 - Jardim Esplanada, 18550-000 Boituva, SP, Brasil. Phone; +55-15-3363-2905. e-mail: renhopp@gmail.com

Received: August 31, 2007 - Modification: March 4, 2008 - Accepted: April 7, 2008

\begin{abstract}
$T_{\text {h }}$

Le aim of this study was to evaluate two root canal filling techniques used in teeth that had their apical foramen disrupted and compare the apical infiltration with an ideal clinical situation. Twenty-seven freshly extracted single-rooted teeth were selected and radiographed to confirm the existence of a single and straight root canal. The crowns were removed at a mean distance of $11 \mathrm{~mm}$ from the apex. The teeth had the root canals instrumented and were randomly assigned to 3 groups (n=9): ND group - root canals were filled using the lateral compaction technique and no disruption was performed; DRF group - the apical constriction was disrupted by advancing a \#40 K-file $1 \mathrm{~mm}$ beyond the original working length, the canals were reinstrumented to create an apical ledge at $1 \mathrm{~mm}$ from the apical foramen and were obturated with a master gutta-percha cone with same size as the last file used for reinstrumentation; DF group - the teeth had the apical constriction disrupted and the canals were obturated with a master gutta-percha cone that fit at $1 \mathrm{~mm}$ from the apex. The teeth were submitted to dye leakage test with Rhodamine B for 7 days, using vaccum on the initial $5 \mathrm{~min}$. The teeth were sectioned longitudinally and the leakage was measured in a linear fashion from apex to crown. There was no statistically significant difference ( $p>0.05)$ between the groups that had the apical foramen disrupted (DF, DRF), but significant difference was found between the disrupted groups and the non-disrupted one $(\mathrm{p}<0.01)$. In conclusion, none of the evaluated techniques was able to prevent apical infiltration, so working length so the working length determination has to be established and maintained carefully.
\end{abstract}

Key words: Root canal filling. Apical infiltration. Apical disruption.

\section{INTRODUCTION}

Resorption or iatrogenic enlargement during instrumentation can result in disruption of the apical constriction. Iatrogenic perforation of the apical constriction can be caused by erroneous determination of the working length (WL). Instrumentation beyond the apical foramen causes damage to the periapical tissues due to extrusion of debris and irrigating solution, and impairs or prevents the adequate seal of the apical foramen, increasing the risk of extrusion of the filling material to the periapical space. If the main objective of endodontic therapy is to create means that lead to the repair of the cementum over the apical foramen, the filling material should not be extruded beyond the root canal into the periapical region $^{21,22}$, although the limit of obturation should be set as close as possible from its termination ${ }^{19}$. Since the exact location of the apical constriction is not determined clinically but histologically, clinicians must be extremely careful not to extrude material beyond it, in order to maintain the integrity of the periapical tissues. It is well accepted that optimal results are obtained when the limit of root canal instrumentation and obturation is set $1 \mathrm{~mm}$ short of the radiographic ape ${ }^{22}$.

Lateral condensation is the most frequently used technique to prevent overfilling. Silva, et al..$^{20}$ observed less overfilling using lateral condensation than thermoplastic techniques, such as Thermafill or backfilling. Al Dewani, et al. ${ }^{1}$ also found less chance of material extrusion and better radiographic quality using cold lateral condensation compared to thermoplasticized techniques.

Two techniques can be used to correct the problem of iatrogenic disruption: the canal can be either reinstrumented to create a new apical ledge, or obturated with a master gutta-percha cone that adapts on the disrupted foramen. The first involves a new determination 
of the WL with thicker files and subsequent obturation. Obturation in these cases can go trough several difficulties, which can lead to extrusion of the filling material into the periapical region. The second technique uses a master gutta percha cone that adapts on the original WL and is thick enough to get stuck on the disrupted foramen. The aim of the present study was to evaluate these two techniques and compare the apical infiltration with an ideal clinical situation, using the lateral compaction technique, in teeth with enlarged apical constriction.

\section{MATERIALAND METHODS}

\section{Tooth Selection and Preparation}

Twenty-seven single-rooted teeth freshly extracted for periodontal reasons were selected and stored in neutral formaldehyde until use. No attempt was made to identify the patient's age or gender. The teeth were radiographed confirm the existence of a single straight root canal. The crowns were sectioned at a mean distance of $11 \mathrm{~mm}$ from the apex and discarded.

\section{Tooth Instrumentation and Obturation}

Instrumentation was held by a single operator. A \#10 K-file (FKG Dentaire, La Chaux-de-Fonds, Switzerland) was introduced into the root canal until it was visible at the apical foramen and the WL was determined at $1 \mathrm{~mm}$ short of this length. Root canal instrumentation was performed using \#0.02 K-files. The canals were irrigated with sodium hypochlorite at each change of file.

After instrumentation, the teeth were randomly assigned to 3 groups of 9 specimens each: Non-disrupted (ND) group - the root canals were filled according to the lateral compaction technique and the apical constriction was not disrupted; Disrupted-reinstrumented-filled (DRF) group - the apical constriction was disrupted by advancing a \#40 K-file $1 \mathrm{~mm}$ beyond the original WL. A new root canal instrumentation was performed to create a new ledge at $1 \mathrm{~mm}$ short of the apex (original WL), starting with a file that fit the new diameter up to a file three sizes greater. Canals were irrigated with sodium hypochlorite at each change of instrument and EDTA was applied for 5 min as a chelating agent at the end of instrumentation. Root canal filling was performed using the lateral condensation technique with a master gutta-percha cone of the same diameter of the last K-file used for instrumentation, accessory gutta-percha points and Sealapex (Sybron Endo, USA). Filling was considered satisfactory when no accessory gutta-percha point could advance more than 1 $\mathrm{mm}$ into the canal; Disrupted-filled (DF) group - The apical constriction was disrupted in the same way as described for the DRF group. However, the canals were not reinstrumented, but only filled with a master gutta-percha cone that fit into the original WL (1 mm short of the apex), accessory gutta-percha points and Sealapex. Filling was considered satisfactory when no accessory gutta-percha point could advance more than $1 \mathrm{~mm}$ into the canal.

\section{Apical Infiltration - Dye Leakage Test}

After instrumentation, the teeth were sealed with nail varnish leaving only the apex free for the dye penetration and were submitted to dye leakage test with Rhodamine B for 7 days, using vacuum in the first $5 \mathrm{~min}$. Thereafter, the teeth were dried, cut longitudinally and the leakage was measured in a linear fashion from apex to crown. Two measures were taken: (1) the distance from the filling to the apex and (2) the penetration of the dye along the filling. Data were analyzed by ANOVA, using Microsoft Excel and Student's t-test to verify the statistical significance of the results $(\alpha=5 \%)$.

\section{RESULTS}

The distance between root apex and filling material and dye leakage extent in the groups are shown in Tables 1, 2, and 3.

The ND group had a mean apex-to-filling distance of $1.29 \pm 0.56 \mathrm{~mm}$, which fits in the original WL, and a dye leakage mean value of $0.13 \pm 0.17 \mathrm{~mm}$. Five specimens in this (55\%) presented no leakage (Tables 1 and 4). The DRF group had a mean apex-to-filling distance of $1.43 \pm 0.24$ $\mathrm{mm}$, and a dye leakage mean value of $0.44 \pm 0.33 \mathrm{~mm}$. Two specimens (22.2\%) presented no leakage (Tables 2 and 5). The DF group had a mean apex-to-filling distance of $1.24 \pm$ $0.54 \mathrm{~mm}$ and a dye leakage mean value of $0.39 \pm 0.21 \mathrm{~mm}$. All specimens showed apical leakage (Tables 3 and 6).

There was no statistically significant difference between the groups that had the apical constriction disrupted (DF, DRF), but significant difference was found between the disrupted groups and the non-disrupted one $(\mathrm{p}<0.05)$

TABLE 1-Apex-to-filling distance ( $\mathrm{mm}$ ) and leakage extent $(\mathrm{mm})$ in the non-disrupted (ND) group

ND Apex-to-filling distance $(\mathrm{mm}) \quad$ Leakage $(\mathrm{mm})$

\begin{tabular}{llc}
\hline 1 & 1.9992 & 0 \\
2 & 1.2936 & 0 \\
3 & 0.9408 & 0.4704 \\
4 & 1.764 & 0.2352 \\
5 & 0.1176 & 0 \\
6 & 1.764 & 0.2352 \\
7 & 1.2936 & 0.2352 \\
8 & 1.4112 & 0 \\
9 & 1.0584 & 0 \\
Mean & 1.2936 & 0.130666667 \\
\hline
\end{tabular}


TABLE 2- Apex-to-filling distance $(\mathrm{mm})$ and leakage extent $(\mathrm{mm})$ in the disrupted-reinstrumented-filled (DRF) group

\begin{tabular}{lll} 
DRF & Apex-to-filling distance $(\mathbf{m m})$ & Leakage $(\mathbf{m m})$ \\
\hline 1 & 1.0584 & 0.2352 \\
2 & 1.6464 & 0.588 \\
3 & 1.764 & 0.4704 \\
4 & 1.6464 & 0 \\
5 & 1.2936 & 0.9408 \\
6 & 1.2936 & 0.8232 \\
7 & 1.176 & 0.588 \\
8 & 1.4112 & 0.3528 \\
9 & 1.6464 & 0 \\
Mean & 1.4373 & 0.4442 \\
\hline
\end{tabular}

TABLE 3- Apex-to-filling distance ( $\mathrm{mm})$ and leakage extent $(\mathrm{mm})$ in the disrupted-filled (DF) group

\begin{tabular}{lll} 
DF & Apex-to-filling distance $(\mathbf{m m})$ & Leakage $(\mathbf{m m})$ \\
\hline 1 & 1.5288 & 0.2352 \\
2 & 1.6464 & 0.4704 \\
3 & 0.3528 & 0.2352 \\
4 & 2.1168 & 0.2352 \\
5 & 1.176 & 0.2352 \\
6 & 1.5288 & 0.2352 \\
7 & 1.2936 & 0.8232 \\
8 & 0.7056 & 0.588 \\
9 & 0.8232 & 0.4704 \\
Mean & 1.2413 & 0.392 \\
\hline
\end{tabular}

TABLE 4- Statistical data for the non-disrupted (ND) group

\begin{tabular}{lll}
\hline ND & Apex-to-filling distance $(\mathbf{m m})$ & Leakage \\
\hline Mean & 1.2936 & 0.1307 \\
SD & 0.5609 & 0.1709 \\
ANOVA & 0.3146 & 0.0291 \\
\hline
\end{tabular}

TABLE 5- Statistical data for the disrupted-reinstrumentedfilled (DRF) group

\begin{tabular}{lll}
\hline DRF & Apex-to-filling distance $(\mathbf{m m})$ & Leakage \\
\hline Mean & 1.4373 & 0.4443 \\
SD & 0.2479 & 0.3315 \\
ANOVA & 0.0615 & 0.1099 \\
\hline
\end{tabular}

TABLE 6- Statistical data for the disrupted-filled (DF) group

\begin{tabular}{lll}
\hline DF & Apex-to-filling distance $(\mathbf{m m})$ & Leakage \\
\hline Mean & 1.2413 & 0.3920 \\
SD & 0.5425 & 0.2120 \\
ANOVA & 0.2943 & 0.0449 \\
\hline
\end{tabular}

\section{DISCUSSION}

The present study focused on the role of the obturation technique when the apical foramen is disrupted, which can clinically occur when the WL is erroneously established or not maintained during the root canal instrumentation. All procedures were performed by a single operator in order to avoid inter-operator discrepancies. Only teeth with a single straight root canal were used because they offer a more standardized method for evaluation of apical leakage. In addition, evaluating the difficulties on management of curved canals was not within the scope of this study.

There is a lot of skepticism regarding the significance of in vitro leakage studies and the limitations of their results ${ }^{25}$. Even so, they are widely used to evaluate and compare the sealability of materials and have an important role for testing prior to clinical use in patients. Although the intensity of the coloration produced after apical infiltration was not an issue in the present experimentation, Rhodamine B was used because it does not suffer discoloration by calcium hydroxide-based materials as occurs with methylene blue ${ }^{25}$. Vacuum was used based on studies that showed greater infiltration when vacuum was used compared to its nonuse, probably due to formation of air pockets in the filling mass, which hinders dye penetration but not bacteria ${ }^{6}$.

Apical constriction disruption mostly happens when WL determination is done in an erroneous way ${ }^{11}$. The WL can be determined either radiographically or electronically ${ }^{4}$. It has been shown that root apex locators offer a more accurate WL determination because not all apical foramens are localized on the root apex, and can be sometimes on the side of the root. The anatomic apex may or may not coincide with the apical foramen. In most cases (50-98\% of all roots), the foramen deviates from the long axis of the tooth ${ }^{15}$.

Weine ${ }^{24}$ stated that the ideal apical limit should be at the 
cemento-dentinal junction (apical constriction) and the practical limit at $1 \mathrm{~mm}$ short of the apex; while other researchers have mentioned only the practical limit of instrumentation and obturation, setting them between 0.5 and $1 \mathrm{~mm}$ short of the apex ${ }^{16}, 1 \mathrm{~mm}$ short of the apex ${ }^{7}$ or at the apical constriction ${ }^{9,12,23,}$. Schaeffer, et al. ${ }^{19}$, observed that teeth obturated 0-1 mm short of the radiographic apex had better healing than those obturated more than $1 \mathrm{~mm}$ from the apex.

The results of the present study showed a mean apexto-filling distance acceptable based the literature, with little deviation from $1 \mathrm{~mm}$ short of the apex. However, given some of apex-to-filling distances had means that were the same, it may be assumed that the greater dye leakage occurred in the disrupted groups was due the diameter of the apical foramen after disruption.

Little has been published about the correlation between apical foramen diameter and apical infiltration, which impairs a direct comparison of the present results to previous ones. The results of this study showed a poorer sealing when the apical foramen was disrupted, probably due to a larger diameter of the apical foramen after disruption, which allowed deeper leakage. Mente, et al. ${ }^{13}$ evaluated the influence of apical enlargement on the sealing ability and observed a positive correlation between apex diameter and more leakage was found in extremely large canals compared smaller ones. When the apical foramen is disrupted, canal shape can be changed and cause apical misfit of the master cone to the canal walls with formation of voids that create paths for dye leakage.

El Ayouti, et al. ${ }^{5}$ showed that despite the correct radiographic determination of WL, overinstrumentation occurred in $51 \%$ of premolars and in $22 \%$ of molars. Although root apex locators are provide a more accurate WL determination than radiographs, the latter are still widely used and neither of the techniques can avoid the WL is lost due to inadvertent disruption of this area. When the apex constriction is disrupted and lateral condensation technique is used, the master gutta-percha must fit to the region of constriction. The master cone can fit a new apical ledge or the dentinal walls without creation of a new apical ledge.

Various techniques are described in the literature to avoid overfilling. The use of dentin chips, calcium hydroxide apical plugs and master cone customization are described in order to maintain the filling material inside of the canal and prevent it from invading the periapical tissues. Allison, et al. ${ }^{2}$, showed that the master cone does not have to get stuck in the apical constriction, which is a clinically difficult maneuver under certain situations. Standardization with calibrating rulers is a fast, practical and useful method. Modeling of the apical end of the gutta-percha master cone can be done with xylol or chloroform, and is a useful technique even though they are considered carcinogenic. However, it was not within the scope of the present study to evaluate the role of cone modeling filling techniques in disrupted teeth.

Lateral condensation is the most frequently used technique to prevent overfilling. Silva, et al. ${ }^{20}$ found less overfilling using lateral condensation than thermoplastic techniques such as Thermafill or backfilling. Another study ${ }^{1}$ also found less possibility of material extrusion and better radiographic quality using cold lateral condensation compared to thermoplasticized techniques. Pérez Heredia, et al. ${ }^{18}$ showed that cold lateral condensation was effective in sealing the apex and presented a greater depth of spreader penetration compared to the thermoplastic technique. Another study ${ }^{8}$ found a larger area of sealer when cold lateral condensation was used compared to the use of Thermafil. Peng L, et al. ${ }^{17}$ found a higher chance of extruding material when warm gutta-percha is used when compared to the lateral compaction technique, but showed no differences in the outcomes of those fillings, while another study ${ }^{10}$ showed that fillings with continuous wave of obturation were more likely to extrude than the cold lateral compaction. Other researchers ${ }^{25}$ demonstrated that there is a higher fluid movement when teeth are filled by the vertical compaction technique that those filled by lateral condensation. In the present study, we also used \#0.02 master gutta-percha cones, which have been shown to allow the spreader to advance to a depth significantly closer to the $\mathrm{WL}^{3}$. In another study, cold lateral compaction achieved a better apical sealing than thermoplasticized techniques ${ }^{14}$.

Still, the diameter of the apical foramen cannot be considered as the only factor for greater leakage. No obturation technique, even if performed as accurately as possible, is still flawless. When the root canal is disrupted, the presence of apical voids is somehow increased because of factors such as dislocation of the obturation, difficulty to get the cone stuck on a newly prepared apical ledge and even canal transportation produced in the moment of disruption, altering the canal shape.

One of the most difficult points of the endodontic treatment is to achieve regularity and standardization. It may take years of practice to achieve a satisfactory level of standardization on the treatment, and this study serves to warn clinicians to that. Care should be exercise until completion of the treatment, which includes maintaining the original WL and canal shaping and avoiding the creation of apical zips or even more severe deviations.

In order to maintain apical regularity, it is important that instrumentation is performed according to all principles of root canal therapy. Apical disruption violates one of these principles, which is to maintain the apical foramen in its original position in order to allow the compaction and accommodation of the filling material on the apical foramen, thus reducing leakage.

The two techniques tested did not differ significantly from each other, but both had poorer results than the notdisrupted situation. These results indicate that the WL has to be precisely determined and maintained to avoid overinstrumentation. Clinicians should follow strictly all principles referring to root canal shaping and WL determination in order to avoid instrumentation beyond the foramen and inadvertent enlargement of this region.

Other root canal filling techniques should be evaluated to determined the best approach for cases of apical foramen disruption. 


\section{CONCLUSIONS}

Based on the results of the present study it may be concluded that none of the evaluated techniques was able to prevent apical infiltration, so the WL must be established and maintained carefully.

\section{REFERENCES}

1- Al-Dewani N, Hayes SJ, Dummer PM. Comparison of laterally condensed and low-temperature thermoplasticized gutta-percha root fillings. J Endod. 2000;26(12):733-8.

2- Allison DA, Michelich RJ, Walton, RE. The influence of master cone adaption on the quality of the apical seal. J Endod. 1981;7(2):615.

3- Bal AS, Hicks ML, Barnett F. Comparison of laterally condensed .06 and .02 tapered Gutta-Percha and sealer in vitro. J Endod. 2001;27(12):786-8.

4- Dahlin, J. Eletrometric measuring of the apical foramen. Quintessence Int Dent Dig. 1979;10(1):13-22.

5 - ElAyouti A, Weiger R, Lost C. Frequency of overinstrumentation with an acceptable radiographic WL. J Endod. 2001;27(1):49-52.

6- Goldman M, Simmonds S, Rush R. The usefulness of dye-penetration studies reexamined. Oral Surg Oral Med Oral Pathol. 1989;67(3):32732

7- Guldener PHA. Importanzia della misurazione endodontica: In: Guldener PHA; Langeland K. Endodontologia, Padova, IT: Piccin; 1985. p. $161-70$

8- Gulsahi K, Cehreli ZC, Kuraner T, Dagli FT. Sealer area associated with cold lateral condensation of gutta-percha and warm coated carrier filling systems in canals prepared with various rotary NiTi systems. Int Endod J. 2007;40(4):275-81.

9- Ingle JI. Endodonzia. Padova, IT: Picchin; 1973. p. 162-3

10- Keçeci AD, Unal GC, Sen BH. Comparison of cold lateral compaction and continuous wave of obturation techniques following manual or rotary instrumentation. 1. Int Endod J. 2005;38(6):381-

11- Lambrianidis T. Risk management in root canal treatment. Thessaloniki: University Studio Press; 2001. p. 175-91

12- Langeland K. The histopatologic basis in endodontic treatment. Dental Clinics of North America. Philadelphia: Saunders;1967. p. 491-520.

13- Mente J, Werner S, Koch MJ, Henschel V, Legner M, Staehle HJ, et al. In vitro leakage associated with three root-filling techniques in large and extremely large root canals. J Endod. 2007;33(3):306-9.

14- Moor RJ, De Boever JG. The sealing ability of an epoxy resin root canal sealer used with five gutta-percha obturation techniques. Endod Dent Traumatol. 2000;16:291-7.

15- Palmer MJ, Weine FS, Healy HJ. Position of the apical foramen in relation to endodontic therapy. J Can Dent Assoc. 1971;37:305-8.

16- Pecchioni A Endodonzia: manuale di tecnica operativa. Milano, IT: I.C.A.; 1983. p. 86-104.
17 - Peng L, Ye L, Tan H, Zhou X. Outcome of root canal obturation by warm gutta-percha versus cold lateral condensation: a metaanalysis. J Endod. 2007;33(2):106-9.

18- Pérez-Heredia M, Clavero-González J, Ferrer-Luque CM, González-Rodríguez MP. Apical seal comparison of low-temperature thermoplasticized gutta-percha technique and lateral condensation with two different master cones. Med Oral Patol Oral Cir Bucal. 2007;12:175-9.

19- Schaeffer MA, White RR, Walton RE. Determining the optimal obturation length: a meta-analysis of literature. J Endod. 2005; 31:2714

20- Silva D, Endal U, Reynaud A, Portenier I, Orstavik D, Haapasalo M. A comparative study of lateral condensation, heat-softened guttapercha, and a modified master cone heat-softened backfilling technique. Int Endod J. 2002;35(12):1005-11.

21- Sjogren U, Hagglund B, Sundqvist G, Wing K. Factors affecting the long term results of endodontic treatment. J Endod. 1990;16(10):498-504.

22- Swartz DB, Skidmore AE, Griffin JA Jr. Twenty years of endodontic success and failure. J Endod. 1983;9(5):198-202.

23- Taylor GN. Tecniche per la preparazione e l'otturazione intracanalare. Clin Odontol N Am. 1988;20(3):566-81.

24- Weine FS. Terapia endodontica. Scienza e tecnica dentistica. Milano, IT: Edizioni Internazionali;1982. p. 183-96.

25- Wu MK, van der Sluis LW, Ardila CN, Wesselink PR. Fluid movement along the coronal two-thirds of root fillings placed by three different gutta-percha techniques. Int Endod J. 2003;36(8):53340 .

26- Wu MK, Wesselink PR. Endodontic leakage studies reconsidered. Part I. Methodology, application and relevance. Int Endod J. 1993;26:37-43. 